\title{
Detection of Parasite Eggs from Archaeological Excavations in the Republic of Korea
}

\author{
Eun-Taek Han, Sang-Mee Guk, Jae-Lip Kim, Hoon-Jin Jeong*, Soo-Nam Kim*, \\ Jong-Yil Chai ${ }^{+}$
}

\begin{abstract}
Department of Parasitology, Seoul National University College of Medicine, and Institute of Endemic Diseases, Seoul National University Medical Research Center, Seoul 110-799, Korea *Corps for the Excavation and Research of Buried Cultural Properties, Foundation for the Preservation of Cultural Properties, Seoul, Korea

Excavations at two sites dating from 2000 BC-1900 AD in southeastern areas of the Republic of Korea, revealed the remains of several structures. Examination of the contents suspected privies revealed the presence of eggs from 5 kinds of parasite: Ascaris, Trichuris, Clonorchis, and two species of unknown trematodes. Clonorchis sinensis eggs were found in a soil dating from around $A D$ 668-935. This is the first record of C. sinensis eggs in archaeological materials in the Republic of Korea.
\end{abstract}

Key words: archaeology - excavation - soil - helminth egg - detection - Korea

Parasitological examinations have been a routine tool of paleo-fecal researches in North and South America (Horne 1985, Kliks 1990, Ferreira et al. 1991, 1993, Schmidt et al. 1992, Araujo \& Ferreira 2000, Faulkner et al. 2000), Europe (Taylor 1955, Grzywinski 1959, Pike 1968, Herrmann 1988, Jones 1985, Greig 1981, Bouchet 1995, Araujo \& Ferreira 2000, Bouchet et al. 2002), as well as Egypt (Ruffer 1910), from the beginning of the century.

In Asian countries, eggs of Ascaris lumbricoides, Trichuris trichiura, Enterobius vermicularis, Clonorchis sinensis, and Schistosoma japonicum have been found in corpses dating from 2100 years ago (Chen 1956, Wei 1973, Chen \& Hung 1981, Wei et al. 1981, Hu 1984, Yang et al. 1984, Su 1987, Wu et al. 1996). In the Republic of Korea, archaeological studies were carried out, for the first time, during the excavation of the wetland site dating from 100 BC, from which Ascaris and Trichuris eggs were recovered (Kwangju National Museum; KNM 1997). With the exception of these two kinds of helminth eggs, there have been no reports of parasites from paleo-fecal research in Korea.

Of helminth infections, soil- and snail-transmitted helminths have been the most common and wide-spread parasites among the Korean population over the last century. There has been only one report on the prevalence of human parasites in the Korean peninsula (KNM 1997). This parasitological analysis aided in the determination of the use of the pits as privies, and hence provided further information about the health and hygiene of the inhabitants of the prehistoric and historic archaeological sites of the Republic of Korea.

This research was supported in part by the Foundation for the Preservation of Cultural Properties and BK21 Human Life Sciences, Republic of Korea.

${ }^{+}$Corresponding author. Fax: +82-2-765.6142. E-mail: cjy@ plaza.snu.ac.kr

Received 26 August 2002

Accepted 25 November 2002

\section{MATERIALS AND METHODS}

We excavated earthen wares dating from 668-935 AD (the Unified Shilla Dynasty) from Chilgok-gun, Taegu-city, and several pieces of ware and hunting tools dating from 2000-1000 BC (Bronze Age), 100 BC-650 AD (Three Kingdoms of Shilla, Koguryo and Paekje), and 1400-1900 AD (Chosen Dynasty) from Ulgin-gun, Kyungsangbuk-do.

One hundred and six pit soil samples were examined from 47 zones in two areas. From one area, located in Chilgok-gun, Taegu-city (Site A), 20 samples from 30 zones, and from another located in Ulgin-gun, Kyungsangbuk-do (Site B), 86 pit samples from 17 zones, were examined.

For the purpose of the helminthological study, approximately $100 \mathrm{~g}$ of soil materials were removed from each pit, stored in tightly sealed vinyl bags and transferred to our laboratory. Each of $10 \mathrm{~g}$ sample was placed in a $50 \mathrm{ml}$ centrifuge tube. All samples were rehydrated in $0.5 \%$ trisodium phosphate solution (Van Cleave \& Ross 1947, Pike 1968), and to ensure rehydration, were completely immersed and shaken vigorously in the solution on a daily basis for one week. The rehydrated soils were filtered through several layers of gauze, and usually accomplished by washing the material with trisodium phosphate solution. After the disintegration the samples were precipitated for one day, with the upper turbid layer being discarded. The soil was dissolved in $20 \mathrm{ml}$ trisodium phosphate solution, and a $20 \mu \mathrm{l}$ sample pipetted onto a microscopic slide, covered with a cover glass $(22 \times 40 \mathrm{~mm})$ and scanned at $\times 100$ magnification to determine the presence of eggs or larvae. At least 10 slides were prepared from each sample. Measurements of eggs were obtained using a stage and ocular micrometers following appropriate calibration.

\section{RESULTS}

Of the 106 pit soil samples examined, 10 contained helminth eggs from two sites (Table, Figs 1-6). These eggs were identified as those of A. lumbricoides (Fig. 1), T. trichiura (Fig. 2), C. sinensis (Fig. 3), and two unknown trematode sp. (Figs 4, 5). 

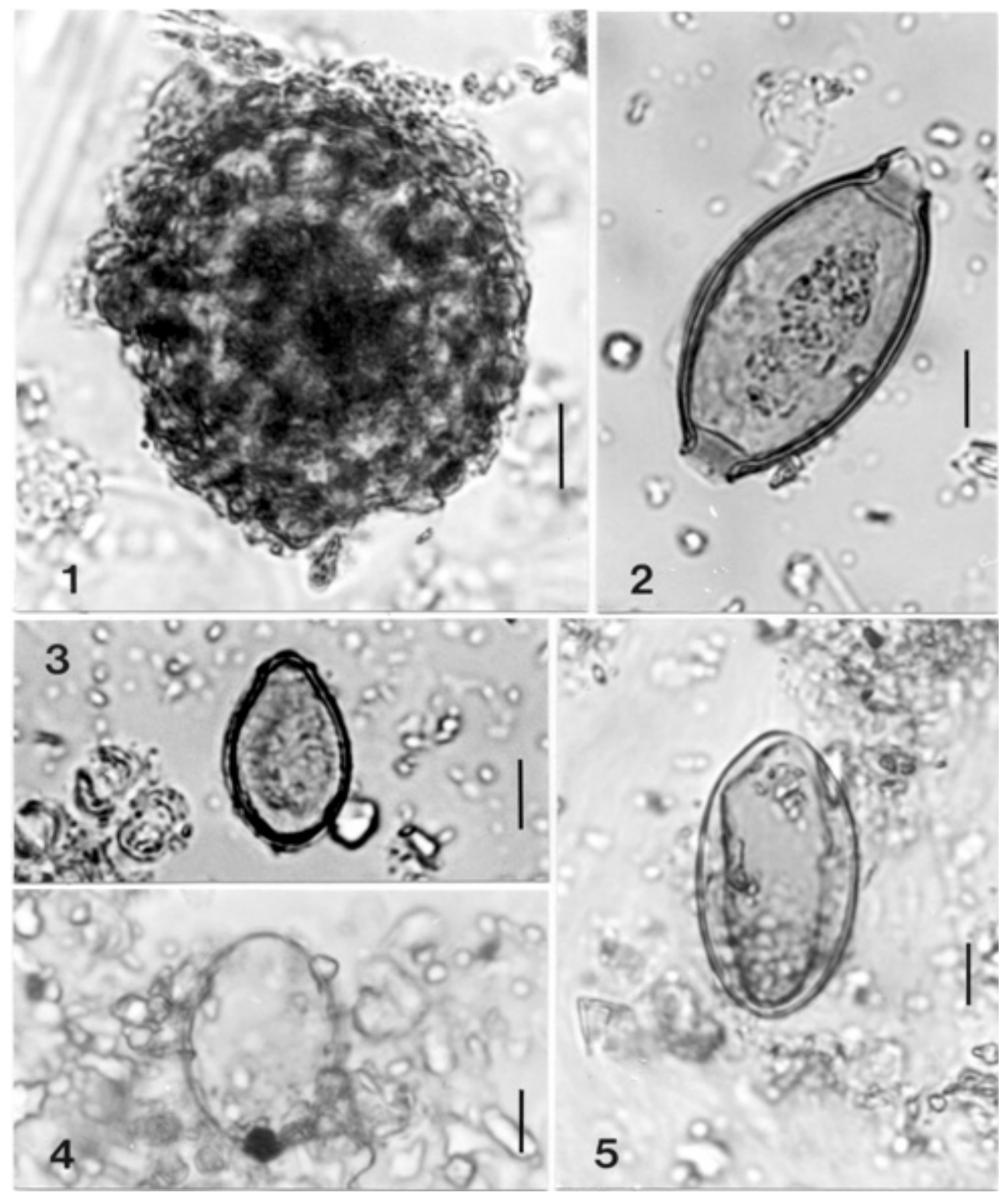

Helminth eggs recorded in soils from suspected privies. Fig. 1: Ascaris lumbricoides (bar $=10 \mu \mathrm{m})$. Fig. 2: Trichuris trichiura $(\mathrm{bar}=10 \mu \mathrm{m})$. Fig. 3: Clonorchis sinensis $(\mathrm{bar}=10 \mu \mathrm{m})$. Fig. 4: unknown trematode sp. $\mathrm{I}(\mathrm{bar}=10 \mu \mathrm{m})$. Fig. 5: unknown trematode sp. II $(\mathrm{bar}=10 \mu \mathrm{m})$.

TABLE

Recovery of helminth eggs in soils from archeological excavations in the Republic of Korea

\begin{tabular}{lccc}
\hline Localities & $\begin{array}{c}\text { Chilgok-gun } \\
(\text { Site A) }\end{array}$ & $\begin{array}{c}\text { Ulgin-gun } \\
(\text { Site B) }\end{array}$ & Size $(\mu \mathrm{m})^{b}$ \\
\hline No. zones (pits) & $20(20)$ & $17(86)$ & 5 \\
No. egg positive zones & 5 & & $55.0 \pm 3.7 \times 49.4 \pm 2.2$ \\
Helminth eggs & & 0 & $49.0 \pm 2.7 \times 24.8 \pm 0.8$ \\
Ascaris lumbricoides & 2 & 0 & $27.7 \pm 2.3 \times 18.8 \pm 4.8$ \\
Trichuris trichiura & 1 & 0 & $34.8 \pm 2.8 \times 26.5 \pm 4.9$ \\
Clonorchis sinensis & 3 & $2^{c}$ & $40.0 \times 22.5$ \\
Unknown trematode sp. I & 0 & $1^{d}$ & \\
Unknown trematode sp. II & 0 & & \\
\hline
\end{tabular}

$a$ : dating from AD 668-935; $b$ : length \pm S.D. (standard deviation) $\times$ width \pm S.D.; $c$ : dating from AD 1400-1900; $d$ : dating from BC 100-AD 650. 
From Site A (Chilgok-gun, Taegu-city), we recovered eggs of A. lumbricoides, T. trichiura and C. sinensis from several $\mathrm{cm}$ to $5 \mathrm{~m}$ below the ancient (668-935 AD) remains. Of the samples collected, eggs of A. lumbricoides, $T$. trichiura and $C$. sinensis, from pit no.1, eggs of $C$. sinensis from pit nos. 3 and 6, and A. lmbricoides from pit no. 11, were recovered. The egg counts per gram of soil sample were approximately 2,800 for $A$. lumbricoides 2,100 for $T$. trichiura and 2,100 for C. sinensis, in pit no. 1, and 2,200 for $C$. sinensis in pit no. 3 .

From Site B (Ulgin-gun, Kyungsangbuk-do) we recovered two kinds of eggs from unknown trematode species from several $\mathrm{cm}$ to 5 meter below the prehistoric remains (2000 BC-1900 AD), and at the existing site. Eggs of 2 unknown trematode species (I and II) were recovered from pits nos. 21 and 59, and eggs of unknown trematode species II from pit no. 62. Parasitological data from the excavated soil samples confirmed that the archaeological Sites $\mathrm{A}$ and $\mathrm{B}$ were, in ancient times, privies.

\section{DISCUSSION}

Paleoarchaeological analyses have been performed to provide some clues as to the dietary behaviors, nutrients and health conditions and the natures of occupation to supplement other archaeological evidence. Desiccated, or mineralized, coprolites and soils, recovered from archaeological sites, are routinely analyzed for parasites. Parasites and/or eggs have been found in archaeological materials, usually from the periods associated with humans (Araujo \& Ferreira 2000).

From only their morphology and size, it is impossible to know if Ascaris sp., Trichuris sp. and C. sinensis eggs are of human or animal origin; but those of $A$. lumbricoides from humans can be differentiated, with much difficulty, from Ascaris suum found in pigs, and those of T. trichiura can be differentiated, with much difficulty, from Trichuris suis (Jones 1982). It is known that the trematodes, e.g. C. sinensis and Metagonimus sp., can infect humans and other mammalian hosts (e.g. wild animals), but it is impossible to know the natural definitive host, based on the size of eggs. The possibility that the recovered trematode eggs, from the excavated areas, coming from either infected wild animals and/or humans can not be excluded. At the archaeological sites in question, other remains proved the existence of human habitation, therefore these parasite eggs could well have originated from humans.

In western countries it has been reported that Ascaris sp. and Trichuris sp. are the most commonly encountered eggs of parasites (Taylor 1955, Pike 1967, 1968, Jones 1982, Aspock et al. 1996). They have been reported from as early as the Neolithic, up to Roman and Saxon eras, in England, Germany, Australia, Holland, Poland, Denmark and Israel.

In Asia, the excavation of eggs from parasites from archaeological materials has been reported in several sources from Korea and China (Chen 1956, Wei 1973, Chen \& Hung 1981, Wei et al. 1981, Hu 1984, Yang et al. 1984, Su 1987, Wu et al. 1996, KNM 1997). In the Republic of Korea only one paleoparasitological study has been carried out, and the helminth eggs, Ascaris sp. and Trichuris sp., were found during the excavation of the wetland sites of Shinchang-dong, Kwangju-city in the southwestern area, dating from $100 \mathrm{BC}$ (KNM 1997). In China, paleoparasitological studies were performed on ancient corpses in 'Tomb No. 1' of the Chu Dynasty at Guo-Jia-Gang, Jingmen City, Hubei Province in the middle stage of the Warring Stages (475-221 BC) (Hu 1984, Yang et al. 1984, Su 1987, Wu et al. 1996), and Western Han Dynasty (206 BC-220 AD) excavated from tomb No. 1 at Ma-Wang-Dui in Changsha City (Wei 1973) and tomb No. 168 at Phoenix Hill in Jinagling City (Chen \& Hung 1981, Wei et al. 1981), and from tomb of Ming Dynasty (1368-1644 AD) in Guangzhou (Chen 1956).

In Korea, the egg positive rate of soil-transmitted helminths in nationwide inhabitants was, until the end of the 1950 s, over $80 \%$, but decreased to $65.4 \%$ (T. trichiura) and $54.9 \%$ (A. lumbricoides) by 1971 , and to $0.2 \%$ and $0.3 \%$ by 1992 (Chai \& Lee 1993). In China, the eggs of $A$. lumbricoides and T. trichiura were found in corpses excavated from an ancient tomb dating over 2000 years (Wei 1973, Hu 1984, Yang et al. 1984, Su 1987, Wu et al. 1996). According to the data of recent nationwide survey of soiltransmitted helminths, the infection rate of $A$. lumbricoides and T. trichiura was $47 \%$ and $20 \%$, respectively, in China (Xu et al. 1995). The archaeological findings from two countries, China and Korea, may be correlated with the recent prevalence of soil-transmitted helminths.

A Chinese archaeologist first found the eggs of $C$. sinensis, in 1956, from coprolites of a Ming Dynasty corpse (buried in 1513) in the suburbs of Guangzhou (Chen 1956). Since then, in 1975, C. sinensis eggs have been found from a corpse of the West Han Dynasty in Jiangling, Hubei Province (Chen \& Hung 1981, Wei et al. 1981), and from a tomb of the Chu Dynasty (Hu 1984, Yang et al. 1984, Su 1987, Wu et al. 1996). In a recent Chinese nationwide survey, the infection rate of $C$. sinensis was still $0.037 \%$ (Yu et al. 1994). In our study we found C. sinensis eggs from the soil of an archaeological excavation in the Republic of Korea. The nationwide prevalence of this parasite was $4.6 \%$ in 1971 and 2.2\% in 1992 (Chai \& Lee 1993).

Of the two areas examined, Site A (Chilgok-gun, Taegucity) is located at the upper basin of the Nagdong River. The $C$. sinensis egg positive rate of the inhabitants in this area was $14.1 \%$ (Seo et al. 1981). According to these previous results and other archaeological excavation data, this area had already suffered an endemic of chonorchiasis over 1200 years ago, where the inhabitants may have eaten raw freshwater fish. The presence of $C$. sinensis eggs found in this present study is the third record of a liver fluke infection in archaeological material worldwide. The results from both this and previous studies, suggests that clonorchiasis has been prevalent over the last 2300 years in Korea and China.

\section{ACKNOWLEDGEMENTS}

To Dr Adauto Araujo (Escola Nacional de Saúde Pública, Fundação Oswaldo Cruz, Rio de Janeiro, Brazil) for his critical review of this manuscript. 


\section{REFERENCES}

Araujo A, Ferreira LF 2000. Paleoparasitology and the antiquity of human host-parasite relationships. Mem Inst Oswaldo Cruz 95 (Suppl. I): 89-93.

Aspock H, Auer H, Picher O 1996. Trichuris trichiura eggs in the neolithic glacier mummy from the Alps. Parasitol Today 12: 255-256.

Bouchet F 1995. Recovery of helminth eggs from archeological excavations of the Grand Louvre (Paris, France). J Parasitol 81: 785-787.

Bouchet F, Harter S, Paicheler JC, Araujo A, Ferreira LF 2002. First recovery of Schistosoma mansoni eggs from a latrine in Europe (15-16th centuries). J Parasitol 88: 404-405.

Chai JY, Lee SH 1993. Recent Trends of Parasitic Infections in Korea. Collected papers on the control of soil-transmitted helminthiases. The Asian Parasite Control Organization, Tokyo 5: 89-97.

Chen LB, Hung T 1981. Scanning electron microscopic view of parasitic worm ova in an ancient corpse. Acta Chin Acad Med Sci 3: 64-65.

Chen XT 1956. Medical Parasitology, Public Health Publication, Beijing, p. 155-156.

Faulkner CT, Cowie SE, Martin PE, Martin SR, Mayes CS, Patton S 2000. Archeological evidence of parasitic infection from the 19th century company town of Fayette, Michigan. J Parasitol 86: 846-849.

Ferreira LF, Araujo A, Confalonieri U, Chame M, Gomez DC 1991. Trichuris eggs in animal coprolites dated from 30,000 years ago. J Parasitol 77: 491-493.

Ferreira LF, Araujo A, Duarte AN 1993. Nematode larvae in fossilized animal coprolites from lower and middle Pleistocene site, Central Italy. J Parasitol 79: 440-442.

Greig J 1981. The investigation of a mediaeval barrel-latrine from Worcester. J Archaeol Sci 8: 265-282.

Grzywinski L 1959. Analysis of feces from the Middle-Age period. Zoologica Polonica 10: 195-199.

Herrmann B 1988. Parasite remains from Mediaeval latrine deposits: an epidemiologic and ecologic approach. Actes des Troisiemes Journees Anthropologiques, Notes et Monographies Techniques. CNRS, Paris, 24: 135-142.

Horne PD 1985. A review of the evidence of human endoparasitism in the pre-Columbian New World through the study of coprolites. J Archaeol Sci 12: 299-310.

Hu SY 1984. Study on the parasite eggs in an ancient corpse from Zhangguo Chu Tomb No. 1 in Mashan brick-field of Jiangling County, Hubei. Chin J Parasitol Parasit Dis 2: 8.

Jones AKG 1982. Human parasite remains; prospects for a quantitative approach. In AR Hall, HK Kenward (eds), Archaeology in the Urban Context, Council for British Archaeology, Research Report No. 43, York, p. 66-70.

Jones AKG 1985. Trichurid ova in archaeological deposits. British Archaeological Reports. International Series 266: 105-119.

Kliks MM 1990. Helminths as heirlooms and souvenirs: a re- view of New World paleoparasitology. Parasitol Today 6: 93-100.

KNM-Kwangju National Museum 1997. Shinchang-dong wetland site I. Report on the Research of Antiquities of the Kwangju National Museum. Kwangju National Museum 33: 159-166.

Pike AW 1967. The recovery of parasite eggs from ancient cesspit and latrine deposits: an approach to the study of early parasite infections. In D Brothwell, AT Sandison (eds), Diseases in Antiquity, CC Thomas Springfield, London, p. 184-188.

Pike AW 1968. Recovery of helminth eggs from archaeological excavations, and their possible usefulness in providing evidence for the purpose of an occupation. Nature 219: 303304.

Ruffer MA 1910. Note on the presence of Bilharzia haematobia in Egyptian mummies of the Twentieth Dynasty (12501000 BC). Br Med J 1: 16.

Schmidt GD, Duszynski DW, Martin PS 1992. Parasites of the extinct shasta ground sloth Nothrotheriops shastensis, in Rampart Cave, Arizona. J Parasitol 78: 811-816.

Seo BS, Lee SH, Cho SY, Chai JY, Hong ST 1981. An epidemiologic study on clonorchiasis and metagonimiasis in riverside areas in Korea. Korean J Parasitol 19: 137-150.

$\mathrm{Su}$ TC 1987. A scanning electron microscopic study on the parasite eggs in an ancient corpse from a tomb of Chu Dynasty, the Warring State, in Jiangling County, Hubei Province. J Tongji Med Univ 7: 63-64.

Taylor EL 1955. Parasitic helminths in mediaeval remains. Vet Rec 67: 216-218.

Van Cleave HJ, Ross JA 1947. A method for reclaiming dried zoological specimens. Science 105: 318.

Xu LQ, Yu SH, Jiang ZX, Yang JL, Lai LQ, Zhang XJ, Zheng CQ 1995. Soil-transmitted helminthiases: nationwide survey in China. Bull WHO 73: 507-513.

Wei DX, Yang WY, Huang SQ, Lu YF, Su TC, Ma JH, Hu WX, Xie NF 1981. Parasitological investigation on the ancient corpse of the Western Han Dynasty unearthed from tomb No. 168 on Phoenix Hill in Jiangling County. Acta Acad Med Wuhan 1: 16-23.

Wei O 1973. Internal organs of a 2100-year-old female corpse. Lancet 24: 1198.

Wu Z, Guan Y, Zhou Z 1996. Study of an ancient corpse of the Warring States period unearthed from Tomb No. 1 at GuoJia Gang in Jingmen City (A comprehensive study). J Tongji Med Univ 16: 1-5, 10 .

Yang WY, Wei DX, Song GF, Wu ZB, Teng RS 1984. Parasitologic investigations on the ancient corpse of Chu dynasty the warring states unearthed from the Ma-zhuan tomb No. 1, Jiangling County. Acta Acad Med Wuhan 14: 43-45.

Yu S, Xu L, Jiang Z, Xu S, Han J, Zhu Y, Chang J, Lin J, Xu F 1994. Report on the first nationwide survey of the distribution of human parasites in China. 1. Regional distribution of parasite species. Chin J Parasitol Parasit Dis 12: 241-247. 